\title{
The Usefulness of Biological and Neuroimaging Markers for the Diagnosis of Early-Onset Alzheimer's Disease
}

\author{
Alessandro Padovani, Nicola Gilberti, and Barbara Borroni \\ Centre for Ageing Brain and Neurodegenerative Disorders, Neurology Unit, University of Brescia, Piazza Spedali Civili 1, \\ 25125 Brescia, Italy \\ Correspondence should be addressed to Alessandro Padovani, formamens@gmail.com
}

Received 17 November 2010; Revised 28 December 2010; Accepted 22 January 2011

Academic Editor: Benedetta Nacmias

Copyright (C) 2011 Alessandro Padovani et al. This is an open access article distributed under the Creative Commons Attribution License, which permits unrestricted use, distribution, and reproduction in any medium, provided the original work is properly cited.

\begin{abstract}
The recent proposed criteria for Alzheimer's Disease (AD) have strongly claimed the usefulness of biological and neuroimaging markers for early identification AD. Cerebrospinal fluid (CSF) Tau/Abeta ratio, hippocampal atrophy, posterior cingulate, and neocortical associative area hypometabolism, or amyloid burden evaluated by $\mathrm{PiB}$ compound, held the premises to increase diagnostic accuracy in the preclinical disease stages. Despite many efforts to identify subjects at risk of developing AD, less attention has been paid to presenile $\mathrm{AD}$ diagnosis. A few data are already available in early onset $\mathrm{AD}$, mainly obtained in cases of monogenic disorder. In this paper, we discuss the current literature on the role of biological and neuroimaging markers in presenile AD.
\end{abstract}

\section{Introduction}

Alzheimer's Disease $(\mathrm{AD})$ is the most common form of neurodegenerative dementia, with an incidence that increases with age [1].

Typically, the core clinical features of $\mathrm{AD}$ are memory impairment, related to early tissue damage within hippocampus and medial temporal lobes [2]. However, AD is rather clinically heterogeneous and there has been increasing awareness of atypical AD forms, which are characterized at disease onset by either language deficits, behavioural disturbances, or visuospatial abnormalities [3-7]. AD may be termed late-onset $\mathrm{AD}$ when the onset of symptoms is at 65 years or later, and early-onset $\mathrm{AD}$ (EOAD) with symptoms beginning before 65 years of age. The atypical presentations are more frequent in EOAD than in late-onset disease. Notwithstanding, the differential diagnosis between EOAD and psychiatric disturbances, metabolic disorders and even other neurodegenerative dementias associated with an early disease onset, namely, frontotemporal dementia (FTD), corticobasal degeneration, and posterior cortical atrophy, is of particular importance in light of the emergence of potential disease modifying therapies in the future.
Recent proposed consensus criteria for AD have underlined the role played by biological and neuroimaging markers for disease diagnosis [8]. Accordingly, cerebrospinal fluid (CSF) Tau/Abeta ratio, hippocampal atrophy as measured by MRI, posterior-cingulated and neocortical-associative area hypometabolism as detected by FDG-PET, and amyloid burden evaluated by $\mathrm{PiB}$ compound have been claimed as the fingerprints of preclinical AD.

However, in spite of the wide body of literature on the accuracy of biological and neuroimaging markers in identifying subjects at risk of developing $\mathrm{AD}$, much less attention has been devoted to EOAD. Different reasons may be addressed for this: first, presenile $\mathrm{AD}$ is a rare disorder as compared to late-onset disease, thus being difficult to collect a reasonable sample of patients to draw reliable results; second, in most of cases, investigators, considering EOAD to be genetically based, give too much attention to genetics determinants and less attention has been paid to biomarkers.

The aim of the present work is to review the available data on the role of biological and neuroimaging tools that might be helpful in carefully detecting EOAD and to discuss the need of future clinical trials to define diagnostic algorithms for EOAD. 


\section{Genetic Diagnosis in Early-Onset Alzheimer's Disease}

The majority of $\mathrm{AD}$ cases are sporadic buta relatively small number of cases (25\%), present familial aggregation (familial $\mathrm{AD}, \mathrm{FAD})$. FAD is typically associated with $\mathrm{EOAD}(60 \%$ of EOAD is familial), with $13 \%$ appearing to be transmitted as a pure genetic, autosomal dominant trait [9].

In the last years, mutations in three genes have been described as the cause of some familial forms of EOAD, and these cases with known pathogenetic mutations are named monogenic AD.

Firstly, in 1991, mutations within the "Amyloid Precursor Protein gene (APP)" on chromosome 21q21.3 were firstly reported, and more than 32 pathogenetic mutations have been described so far (http://www.molgen.ua.ac.be/ ADMutations). APP mutations account for less than $5 \%$ of autosomal dominant EOAD [9]. The APP gene encodes for a polypeptide of 770 amino acids that may be involved in nuclear signaling [10]. It has been shown that APP protein can be processed by at least two separate pathways, one involves $\alpha$-secretases cleavage and the other requires sequential proteolysis by $\beta$ - and $\gamma$-secretases to generate $\mathrm{A} \beta_{40-43}$ peptides [11]. A $\beta_{42-43}$ were considered the more neurotoxic isoforms and were found increased in the brains of $\mathrm{AD}$ patients [12]. Interestingly, pathogenetic mutations within $A P P$ gene are clustered very close the secretase cleavage sites, thus exerting a direct effect on APP processing [13].

Families with APP mutations show variable age of onset ranging from 31 to 60 years and are clinically defined by EOAD frequently associated with cerebral amyloid angiopathy [14]; some cases have been reported with atypical clinical presentation at symptom onset, resembling Dementia with Lewy Bodies or epilepsy $[15,16]$.

Some years later to the identification of APP mutations, pathogenetic variations within "Presenilin 1gene (PSEN1)" on chromosome $14 \mathrm{q} 24.3$ were identified as key to disease pathogenesis. PSEN1 mutations represent the most common cause of autosomal dominant EOAD (18-50\%), and more than 180 mutations have been identified $[17,18]$.

PSEN1 gene encodes a transmembrane protein of 476 amino acids that acts as catalytic for the $\gamma$-secretase complex. The majority of the known mutations are missense substitutions and show almost complete penetrance by the age 60 years [19].

PSEN1 mutations have been associated with a wide range in age of onset, ranging from very early-onset (before age 30 years) to cases with onset later than 80 years old $[18,20,21]$. It has been demonstrated that carrying PSEN1 mutations is a negative prognostic factor on survival as compared to PSEN2 mutations or sporadic late-onset $\mathrm{AD}[22]$.

Phenotypic heterogeneity is common in patients with PSEN1 mutations. Although the majority of known PSEN1 genetic variations are associated with classical EOAD, several cases have been reported to have atypical features, namely, myoclonus and seizures $[23,24]$, extrapyramidal signs [23], behavioural and psychiatric symptoms, early aphasia [23, $25]$, visual agnosia [26], cerebellar ataxia $[27,28]$, and spastic paraparesis $[23,29]$.
Conversely, the third gene responsible for autosomal dominant-inherited disorder, that is, "Presenilin 2 (PSEN2)" maps on chromosome 1q31-42, and it does not represent a common cause of EOAD. Only 14 pathogenic mutations have been described so far [30, 31]. PSEN2 gene encodes for a transmembrane protein of 448 amino acids that, as PSEN1, plays a role as a catalytic core of the $\gamma$-secretase complex.

The clinical phenotype associated with PSEN2 mutations is still not clearly defined, as a few cases are available. Up to now, 7 out of 14 mutations are likely to be pathogenetic [22] and they have been associated with $\mathrm{AD}$ with age at onset ranging from 39 to 75 years.

Some mutations were associated with atypical or distinctive clinical features: A85V mutation was described in a family with dementia and parkinsonism and with a clinical diagnosis of Dementia with Lewy Bodies in one member; T122R mutation was reported in subjects with frontotemporal dementia-like phenotype [32], whilst N141I mutation was associated with seizures in 32\% of carriers [3033]. Twelve patients carrying N141I mutation underwent neuropsychological testing and memory loss and impairment in verbal fluency, spatial perception deficits, acalculia, and executive dysfunctions were reported.

In summary, $\mathrm{EOAD}$ accounts for $1-5 \%$ of $\mathrm{AD}$ cases [34]. It has been shown that mutations within APP, PSEN1, or PSEN2 (see Table 1) can explain up to $71 \%$ of the autosomal dominant transmission pattern in FEOAD [35]. The screening for known pathogenetic mutations, in patients with appropriate phenotype and familial EOAD with autosomal dominanttransmission pattern, should be considered useful in clinical practice, but it should be accompanied by neurogenetic counselling and undertaken only after full consent and by specialist centres.

It is however true that the wide spectrum of clinical symptoms of monogenic $\mathrm{AD}$, beyond memory disturbances, claims for the need of biological and neuroimaging markers that can be of help in suggesting DNA sequencing. Moreover, most of EOAD cases are not explained by known Mendelian mutations, and also in these cases there is a need for biomarkers for an accurate diagnosis.

\section{Biological and Neuroimaging Markers in Detecting Early-Onset Alzheimer's Disease}

The recent published criteria for AD have strongly supported the usefulness of biological and neuroimaging markers for improving diagnostic accuracy in preclinical stages [9].

It is well established that reduced CSF Abeta42 levels and increased CSF Tau levels are the signature of AD. In the same way, hypometabolism of posterior cingulate cortex and temporoparietal regions and hippocampal atrophy are the neuroimaging hallmark of the disease [8].

However, the usefulness of these markers in EOAD has been poorly tested, and no reliable large sample size studies in EOAD patients compared to other neurodegenerative dementias are available yet. 
TABle 1: Monogenic forms of Early-Onset Alzheimer's Disease (EOAD).

\begin{tabular}{llll}
\hline Gene & Locus & $\mathrm{N}^{\circ}$ mutations & Clinical presentation \\
\hline APP & $21 \mathrm{q} 21.3$ & 32 & $\begin{array}{l}\text { Onset from } 31 \text { to } 60 \text { years. } \\
\text { EOAD frequently associated with cerebral amyloid angiopathy }\end{array}$ \\
\hline PSEN1 & $14 \mathrm{q} 24.3$ & $\begin{array}{l}\text { Onset before age } 30 \text { years to cases with onset later than } 80 \text { years } \\
\text { old. }\end{array}$ \\
& 180 & $\begin{array}{l}\text { Classical EOAD, several cases with atypical features: myoclonus } \\
\text { and seizures, extrapyramidal signs, behavioural and psychiatric } \\
\text { symptoms, early aphasia, visual agnosia, cerebellar ataxia, and } \\
\text { spastic paraparesis. }\end{array}$ \\
\hline PSEN2 & $1431-42$ & $\begin{array}{l}\text { Onset from } 39 \text { to } 75 \text { years. } \\
\text { Atypical features: dementia and parkinsonism, frontotemporal } \\
\text { dementia-like phenotype, seizures. }\end{array}$ \\
\hline
\end{tabular}

APP: amyloid precursor protein; PSEN: presenilin.

3.1. Cerebrospinal Fluid for EOAD Diagnosis. Sporadic and FAD share common pathogenetic mechanisms, as neurotoxic forms of amyloid appear to be elevated in both cases. Thus, it can be hypothesised that CSF analysis might be of help in EOAD as well. The current findings on CSF markers are based on case reports and small samples of EOAD mutation carriers, namely with PSEN1 genetic variations.

To date, more than 180 mutations in PSEN1 have been detected (http://www.molgen.ua.ac.be/ADMutations). It has been reported that pathogenetic PSEN1 genetic variations lead to significant increases in plasma Abeta42 levels and massive amyloid deposition in the brain [36,37]. A role of PSEN1 mutations in Tau pathology has also been suggested by the finding of tau hyperphosphorylation in PSEN1 transgenic mice [38].

In a recent work, it has been demonstrated that in a case of presenile dementia, spastic paraparesis, and frontal executive function impairment, CSF analysis facilitated DNA diagnosis. Increased CSF total Tau levels and decreased CSF Abeta42 dosage distinguished this familial EOAD from Creutzfeldt Jacob disease and frontotemporal dementia [39]. A causative PSEN1 L424R mutation was subsequently identified [39].

In the same view, a CSF pattern resembling that found in late-onset $\mathrm{AD}$ pointed towards genetic analysis in a case of PSEN1 Q223R mutation [40]; the patient presented familial early-onset dementia at the age of 35 years along with spastic paraplegia and behavioural symptoms.

Interestingly, CSF biomarkers have been demonstrated useful not only in distinguishing EOAD from other neurodegenerative dementias, but also in predicting $\mathrm{AD}$-related mutations in cases with clinical and skin biopsy features suggestive for storage disease [41]. A patient with progressive cognitive decline associated with delusions, myoclonus, and seizure and with no family history for dementia was diagnosed as cereidolipofuscinosis; once CSF analysis was carried out and AD-like pattern reported, de-novo PSEN1 P117L mutation was identified and the diagnosis of EOAD made.

Up to now, no extensive data on CSF analysis in PSEN2 carriers have been performed, as rare causes of EOAD.
However, in a case of PSEN2 N141I mutation, the CSF pattern was comparable to sporadic AD.

3.2. Functional Neuroimaging for EOAD Diagnosis. If in both $\mathrm{EOAD}$ and in sporadic late-onset $\mathrm{AD}, \mathrm{CSF}$ data are almost comparable, different findings may be obtained when neuroimaging markers are considered.

Little is known about the usefulness of neuroimaging in the differential diagnosis with other neurodegenerative dementias. In fact, it has been widely demonstrated that the cognitive pattern of EOAD is different from late-onset $\mathrm{AD}$, in the former the neocortical functions are more affected. Accordingly, EOAD and late-onset AD differ in their typical topographic patterns of brain atrophy [42].

Indeed, in monogenic EOAD cases, neuroimaging reports usually show the pattern of sporadic $\mathrm{AD}$, involving temporoparietal areas, but extra brain regions not commonly observed in typical $\mathrm{AD}$ cases are described. It has been demonstrated that patients with EOAD due to PSEN1 mutations (i.e., His163Tyr) showed greater hypometabolism not only in the posterior cingulate but in frontal cortex as well [43] and thalamic hypometabolism was found in EOAD case carrying APP Val717Ile mutation [44].

Some authors evaluated the role of PiB-compound, a Positron Emission Tomography (PET) tracer binding amyloid, in early diagnosis of EOAD. In a PSEN1 His163Tyr case, $\mathrm{PiB}$ binding was comparable to sporadic $\mathrm{AD}$, but slightly higher striatal levels were detected [43]. The same findings were obtained evaluating ten PSEN1 mutation carriers, with intense and focal PiB retention in the striatum [45]. Moreover, in most PSEN1 mutation carriers, there also were increases in $\mathrm{PiB}$ retention compared to controls in cortical brain areas, but these increases were not as great as those observed in sporadic AD subjects [45].

Another interesting work aimed at evaluating PiB distribution in EOAD in seven PSEN1 mutation carriers and one APP mutation carrier [46]: the authors demonstrated that all mutation carriers had high $\mathrm{PiB}$ retention in the striatum, with some also having cortical $\mathrm{PiB}$ retention in ventrofrontal and posterior cingulate/precuneus areas. The striatal pattern 
of $\mathrm{PiB}$ retention was similar in the PSEN1 and APP mutation carriers [46].

These studies suggested that the pattern of Abeta deposition in FAD differs from that in sporadic AD, with higher striatal and somewhat lower cortical PiB retention in FAD.

\subsection{Structural Neuroimaging for EOAD Diagnosis. Studies} on structural neuroimaging have strongly supported the usefulness of hippocampal measures in early diagnosis of AD. From pathological and MRI studies, the hippocampus is known to be severely affected in established AD $[47,48]$. Hippocampal volumes have consistently been shown to be reduced by as much as $40 \%$ in patients with clinically diagnosed $\mathrm{AD}$, the extent of atrophy correlating with disease severity [49]. Hippocampal atrophy has been introduced in current proposed criteria for preclinical diagnosis of $\mathrm{AD}$ $[8,50]$.

In EOAD, the available data seem to suggest that evaluating hippocampal atrophy may be of help.

In a case of PSEN1 S170F mutation, cortical brain atrophy, particularly within hippocampus, frontal and temporal cortex, was reported [51]. However, as demonstrated, patients with EOAD showed greater neocortical atrophy at the temporoparietal junction, while the patients with lateonset $\mathrm{AD}$ showed greater hippocampal atrophy [52]. Taken together, these results argue that hippocampus evaluation is a signature in EOAD as in late-onset disease.

3.4. Biological and Neuroimaging Markers in Presymptomatic Subjects with EOAD. A few studies have estimated the importance of biological and neuroimaging markers in presymptomatic subjects with known mutations. As, in these, casesgenetic testing is exhaustive, the role of markers has not been fully elucidated. Indeed, the assessment of biological and neuroimaging markers in presymptomatic subjects carrying pathogenetic mutations might be of help in defining the time of conversion. Diagnosis in subjects carrying pathogenetic mutations represents a very delicate aspect with even profound ethical implications that should be treated cautiously and only in the frame of controlled research protocols.

The usefulness of CSF biomarkers has been tested on six presymptomatic subjects with pathogenetic mutations in the PSEN1 gene [53], and CSF Abeta42 levels were found to be significantly lower than age-matched control group. No other data are still available.

Studies in presymptomatic carriers employing imaging techniques like PET and single photon emission computed tomography have revealed regional abnormalities in cerebral glucose metabolism [54] and brain blood-flow [55] prior to the development of clinically significant impairment. Likewise, very early pathological changes in terms of amyloid deposition have been shown in a study of young presymptomatic PSEN1 carriers by using 11C-PiB-PET [45]. A recent study carried out in presymptomatic and mildly affected PSNE1 carriers revealed significantly greater thalamic retention than sporadic AD [56]. Moreover, a few individuals with PSNE1 mutations showed increased cerebellar 11C-PiB retention suggesting that this region may not be as suitable as a reference region in FAD [56].

Finally, volumetric measurement of hippocampus showed asymmetrical atrophy in seven presymptomatic APP Val717Ile carriers [52].

\section{Conclusions}

A few efforts have been addressed to elucidate the usefulness of biological and neuroimaging markers in EOAD. Studies involving larger numbers of individual are required in order to determine whether and which marker abnormalities are consistently detected at early disease stage in young onset dementia. Up to now, no clear-cut conclusions might be drawn.

Preliminary data suggest that CSF markers, such as Abeta and Tau levels, may be considered as a helpful tool in the diagnosis of EOAD, as the reported changes are comparable to those detected in sporadic late-onset AD. Hippocampal measurement seems to be early affected in EOAD, thus to be considered in diagnostic workup. Conversely, more data on functional abnormalities in EOAD are required, as peculiar pattern of hypometabolism/amyloid accumulation occurs in the available EOAD cases associated with monogenic mutations.

The assessment of biomarkers in EOAD should be recommended in order to increase diagnostic accuracy in those cases with atypical presentation and/or familial aggregation of the disease. Biological and neuroimaging markers may be of help to suggest DNA sequencing of known causative genes or to support diagnosis of EOAD in those cases without APP, PSEN1, and PSEN2 mutations.

\section{References}

[1] G. McKhann, D. Drachman, and M. Folstein, "Clinical diagnosis of Alzheimer's disease: report of the NINCDS-ADRDA work group under the auspices of Department of Health and Human Services Task Force on Alzheimer's disease," Neurology, vol. 34, no. 7, pp. 939-944, 1984.

[2] H. Braak and E. Braak, "Demonstration of amyloid deposits and neurofibrillary changes in whole brain sections," Brain Pathology, vol. 1, no. 3, pp. 213-216, 1991.

[3] C. J. Galton, K. Patterson, J. H. Xuereb, and J. R. Hodges, "Atypical and typical presentations of Alzheimer's disease: a clinical, neuropsychological, neuroimaging and pathological study of 13 cases," Brain, vol. 123, no. 3, pp. 484-498, 2000.

[4] S. Alladi, J. Xuereb, T. Bak et al., "Focal cortical presentations of Alzheimer's disease," Brain, vol. 130, no. 10, pp. 2636-2645, 2007.

[5] D. F. Benson, "The spectrum of dementia: a comparison of the clinical features of AIDS/dementia and dementia of the Alzheimer type," Alzheimer Disease and Associated Disorders, vol. 1, no. 4, pp. 217-220, 1987.

[6] J. A. Knibb, J. H. Xuereb, K. Patterson, and J. R. Hodges, "Clinical and pathological characterization of progressive aphasia," Annals of Neurology, vol. 59, no. 1, pp. 156-165, 2006.

[7] J. K. Johnson, E. Head, R. Kim, A. Starr, and C. W. Cotman, "Clinical and pathological evidence for a frontal variant of 
Alzheimer disease," Archives of Neurology, vol. 56, no. 10, pp. 1233-1239, 1999.

[8] B. Dubois, H. H. Feldman, C. Jacova et al., "Research criteria for the diagnosis of Alzheimer's disease: revising the NINCDSADRDA criteria," Lancet Neurology, vol. 6, no. 8, pp. 734-746, 2007.

[9] A. Goate, M. C. Chartier-Harlin, M. Mullan et al., "Segregation of a missense mutation in the amyloid precursor protein gene with familial Alzheimer's disease," Nature, vol. 349, no. 6311, pp. 704-706, 1991.

[10] H. Steiner and C. Haass, "Nuclear signaling: a common function of presenilin substrates?" Journal of Molecular Neuroscience, vol. 17, no. 2, pp. 193-198, 2001.

[11] J. Hardy, "Amyloid, the presenilins and Alzheimer's disease," Trends in Neurosciences, vol. 20, no. 4, pp. 154-159, 1997.

[12] J. A. Hardy and G. A. Higgins, "Alzheimer's disease: the amyloid cascade hypothesis," Science, vol. 256, no. 5054, pp. 184-185, 1992.

[13] M. Mullan, F. Crawford, K. Axelman et al., "A pathogenic mutation for probable Alzheimer's disease in the APP gene at the N-terminus of $\beta$-amyloid," Nature Genetics, vol. 1, no. 5, pp. 345-347, 1992.

[14] L. Cabrejo, L. Guyant-Maréchal, A. Laquerrière et al., "Phenotype associated with APP duplication in five families," Brain, vol. 129, no. 11, pp. 2966-2976, 2006.

[15] P. Pasalar, H. Najmabadi, A. R. Noorian et al., "An Iranian family with Alzheimer's disease caused by a novel APP mutation (THr714ALa)," Neurology, vol. 58, no. 10, pp. 15741575, 2002.

[16] I. Guyant-Marechal, E. Berger, A. Laquerrière et al., "Intrafamilial diversity of phenotype associated with app duplication," Neurology, vol. 71, no. 23, pp. 1925-1926, 2008.

[17] M. Cruts and C. Van Broeckhoven, "Presenilin mutations in Alzheimer's disease," Human Mutation, vol. 11, no. 3, pp. 183190, 1998.

[18] R. Sherrington, E. I. Rogaev, Y. Liang et al., "Cloning of a gene bearing missense mutations in early-onset familial Alzheimer's disease," Nature, vol. 375, no. 6534, pp. 754-760, 1995.

[19] A. Tandon, E. Rogaeva, M. Mullan, and P. H. George, "Molecular genetics of Alzheimer's disease: the role of $\beta$ amyloid and the presenilins," Current Opinion in Neurology, vol. 13, no. 4, pp. 377-384, 2000.

[20] W. K. Dowjat, I. Kuchna, T. Wisniewski, and J. Wegiel, "A novel highly pathogenic Alzheimer presenilin-1 mutation in codon 117 (Pro117Ser): comparison of clinical, neuropathological and cell culture phenotypes of Pro117Leu and Pro117Ser mutations," Journal of Alzheimer's Disease, vol. 6, no. 1, pp. 3143, 2004.

[21] G. Devi, A. Fotiou, D. Jyrinji et al., "Novel presenilin 1 mutations associated with early onset of dementia in a family with both early-onset and late-onset Alzheimer disease," Archives of Neurology, vol. 57, no. 10, pp. 1454-1457, 2000.

[22] S. Jayadev, J. B. Leverenz, E. Steinbart et al., "Alzheimer's disease phenotypes and genotypes associated with mutations in presenilin 2," Brain, vol. 133, no. 4, pp. 1143-1154, 2010.

[23] D. M.A. Mann, S. M. Pickering-Brown, A. Takeuchi et al., "Amyloid angiopathy and variability in amyloid $\beta$ deposition is determined by mutation position in presenilin-1-linked Alzheimer's disease," American Journal of Pathology, vol. 158, no. 6, pp. 2165-2175, 2001.

[24] H. Furuya, M. Yasuda, K. J. Terasawa et al., "A novel mutation (L250V) in the presenilin 1 gene in a Japanese familial Alzheimer's disease with myoclonus and generalized convulsion," Journal of the Neurological Sciences, vol. 209, no. 1-2, pp. 75-77, 2003.

[25] T. H. Lampe, T. D. Bird, D. Nochlin et al., "Phenotype of chromosome 14-linked familial Alzheimer's disease in a large kindred," Annals of Neurology, vol. 36, no. 3, pp. 368-378, 1994.

[26] R. J. Harvey, D. Ellison, J. Hardy et al., "Chromosome 14 familial Alzheimer's disease: the clinical and neuropathological characteristics of a family with a leucine $\rightarrow$ serine (L250S) substitution at codon 250 of the presenilin 1 gene," Journal of Neurology Neurosurgery and Psychiatry, vol. 64, no. 1, pp. 4449, 1998.

[27] U. Finckh, T. Müller-Thomsen, U. Mann et al., "High prevalence of pathogenic mutations patients with early-onset dementia detected by sequence analyses of four different genes," American Journal of Human Genetics, vol. 66, no. 1, pp. 110-117, 2000.

[28] B. Dermaut, S. Kumar-Singh, C. De Jonghe et al., "Cerebral amyloid angiopathy is a pathogenic lesion in Alzheimer's disease due to a novel presenilin 1 mutation," Brain, vol. 124, no. 12, pp. 2383-2392, 2001.

[29] S. Hattori, K. Sakuma, Y. Wakutani et al., "A novel presenilin 1 mutation $(\mathrm{Y} 154 \mathrm{~N})$ in a patient with early onset Alzheimer's disease with spastic paraparesis," Neuroscience Letters, vol. 368, no. 3, pp. 319-322, 2004.

[30] E. Levy-Lahad, W. Wasco, P. Poorkaj et al., "Candidate gene for the chromosome 1 familial Alzheimer's disease locus," Science, vol. 269, no. 5226, pp. 973-977, 1995.

[31] E. I. Rogaev, R. Sherrington, E. A. Rogaeva et al., "Familial Alzheimer's disease in kindreds with missense mutations in a gene on chromosome 1 related to the Alzheimer's disease type 3 gene," Nature, vol. 376, no. 6543, pp. 775-778, 1995.

[32] U. Finckh, C. Kuschel, M. Anagnostouli et al., "Novel mutations and repeated findings of mutations in familial Alzheimer disease," Neurogenetics, vol. 6, no. 2, pp. 85-89, 2005.

[33] E. S. Walker, M. Martinez, A. L. Brunkan, and A. Goate, "Presenilin 2 familial Alzheimer's disease mutations result in partial loss of function and dramatic changes in A $\beta$ 42/40 ratios," Journal of Neurochemistry, vol. 92, no. 2, pp. 294-301, 2005.

[34] R. L. Nussbaum and C. E. Ellis, "Alzheimer's disease and Parkinson's disease," New England Journal of Medicine, vol. 348, no. 14, pp. 1356-1364, 2003.

[35] N. Ertekin-Taner, "Genetics of Alzheimer's disease: a centennial review," Neurologic Clinics, vol. 25, no. 3, pp. 611-667, 2007.

[36] C. A. Lemere, F. Lopera, K. S. Kosik et al., “The E280A presenilin 1 Alzheimer mutation produces increased $\mathrm{A} \beta 42$ deposition and severe cerebellar pathology," Nature Medicine, vol. 2, no. 10, pp. 1146-1150, 1996.

[37] T. Iwatsubo, "A $\beta 42$, presenilins, and Alzheimer's disease," Neurobiology of Aging, vol. 19, no. 1, pp. S11-S13, 1998.

[38] A. Boutajangout, K. Leroy, N. Touchet et al., "Increased tau phosphorylation but absence of formation of neurofibrillary tangles in mice double transgenic for human tau and Alzheimer mutant (M146L) presenilin-1," Neuroscience Letters, vol. 318, no. 1, pp. 29-33, 2002.

[39] S. T. De Bot, H. P. H. Kremer, D. Dooijes, and M. M. Verbeek, "CSF studies facilitate DNA diagnosis in familial alzheimer's disease due to a presenilin-1 mutation," Journal of Alzheimer's Disease, vol. 17, no. 1, pp. 53-57, 2009.

[40] I. Uttner, J. Kirchheiner, H. Tumani et al., "A novel presenilin1 mutation (Q223R) associated with early onset Alzheimer's disease, dysarthria and spastic paraparesis and decreased 
Abeta levels in CSF," European Journal of Neurology, vol. 17, no. 4, pp. 631-633, 2010.

[41] A. Alberici, C. Bonato, B. Borroni et al., "Dementia, delusions and seizures: storage disease or genetic AD?" European Journal of Neurology, vol. 14, no. 9, pp. 1057-1059, 2007.

[42] G. B. Frisoni, M. Pievani, C. Testa et al., "The topography of grey matter involvement in early and late onset Alzheimer's disease," Brain, vol. 130, no. 3, pp. 720-730, 2007.

[43] M. Schöll, O. Almkvist, K. Axelman et al., "Glucose metabolism and PIB binding in carriers of a His163Tyr presenilin 1 mutation," Neurobiology of Aging. In press.

[44] M. N. Rossor, S. Newman, R. S. Frackowiak et al., "Alzheimer's disease families with amyloid precursor protein mutations," Annals of the New York Academy of Sciences, vol. 695, no. 23, pp. 198-202, 1993.

[45] W. E. Klunk, J. C. Price, C. A. Mathis et al., "Amyloid deposition begins in the striatum of presenilin-1 mutation carriers from two unrelated pedigrees," Journal of Neuroscience, vol. 27, no. 23, pp. 6174-6184, 2007.

[46] V. L. Villemagne, S. Ataka, T. Mizuno et al., "High striatal amyloid $\beta$-peptide deposition across different autosomal Alzheimer disease mutation types," Archives of Neurology, vol. 66, no. 12, pp. 1537-1544, 2009.

[47] H. Braak, E. Braak, and J. Bohl, "Staging of Alzheimer-related cortical destruction," European Neurology, vol. 33, no. 6, pp. 403-408, 1993.

[48] C. R. Jack, R. C. Petersen, P. C. O’Brien, and E. G. Tangalos, "MR-based hippocampal volumetry in the diagnosis of Alzheimer's disease," Neurology, vol. 42, no. 1, pp. 183-188, 1992.

[49] M. P. Laakso, H. Soininen, K. Partanen et al., "Volumes of hippocampus, amygdala and frontal lobes in the MRI-based diagnosis of early Alzheimer's disease: correlation with memory functions," Journal of Neural Transmission. Parkinson's Disease and Dementia Section, vol. 9, no. 1, pp. 73-86, 1995.

[50] S. J. Teipel, T. Meindl, L. Grinberg, H. Heinsen, and H. Hampel, "Novel MRI techniques in the assessment of dementia," European Journal of Nuclear Medicine and Molecular Imaging, vol. 35, supplement 1, pp. S58-S69, 2008.

[51] M. P. Golan, M. Styczyńska, K. Jóźwiak et al., "Early-onset Alzheimer's disease with a de novo mutation in the presenilin 1 gene," Experimental Neurology, vol. 208, no. 2, pp. 264-268, 2007.

[52] N. C. Fox, E. K. Warrington, J. M. Stevens, and M. N. Rossor, "Atrophy of the hippocampal formation in early familial Alzheimer's disease: a longitudinal MRI study of atrisk members of a family with an amyloid precursor protein 717 mutation," Annals of the New York Academy of Sciences, vol. 777, pp. 226-232, 1996.

[53] M. Moonis, J. M. Swearer, M. P. E. Dayaw et al., "Familial Alzheimer disease: decreases in CSF A $\beta$ levels precede cognitive decline," Neurology, vol. 65, no. 2, pp. 323-325, 2005.

[54] L. Mosconi, S. Sorbi, M. J. De Leon et al., "Hypometabolism exceeds atrophy in presymptomatic early-onset familial Alzheimer's disease," Journal of Nuclear Medicine, vol. 47, no. 11, pp. 1778-1786, 2006.

[55] K. A. Johnson, F. Lopera, K. Jones et al., "Presenilin1 -associated abnormalities in regional cerebral perfusion," Neurology, vol. 56, no. 11, pp. 1545-1551, 2001.

[56] W. D. Knight, A. A. Okello, N. S. Ryan et al., "Carbon11-Pittsburgh compound B positron emission tomography imaging of amyloid deposition in presenilin 1 mutation carriers," Brain, vol. 134, no. 1, pp. 293-300, 2011. 


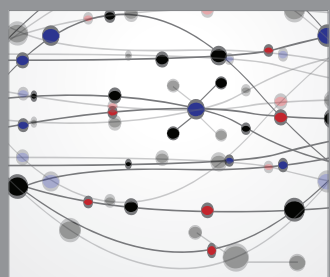

The Scientific World Journal
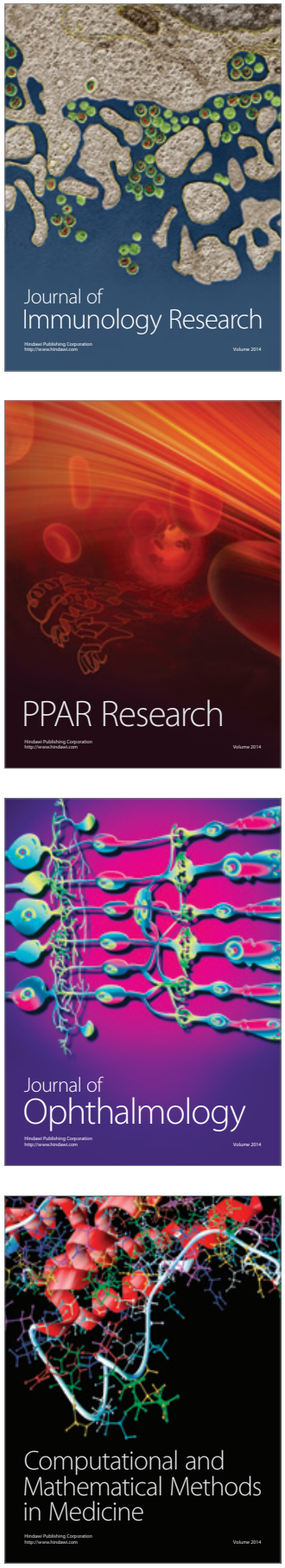

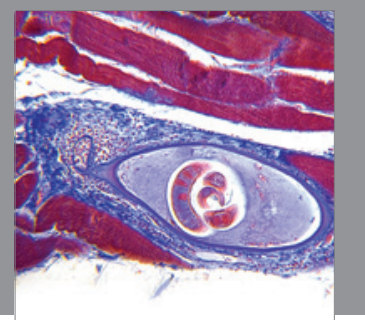

Gastroenterology

Research and Practice
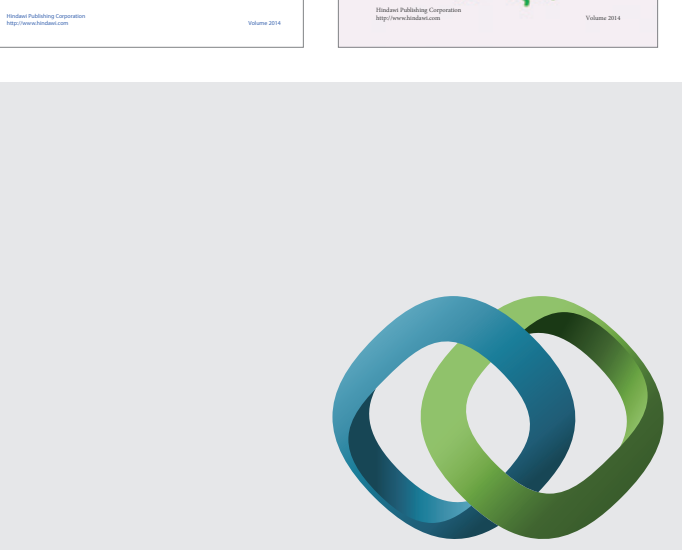

\section{Hindawi}

Submit your manuscripts at

http://www.hindawi.com
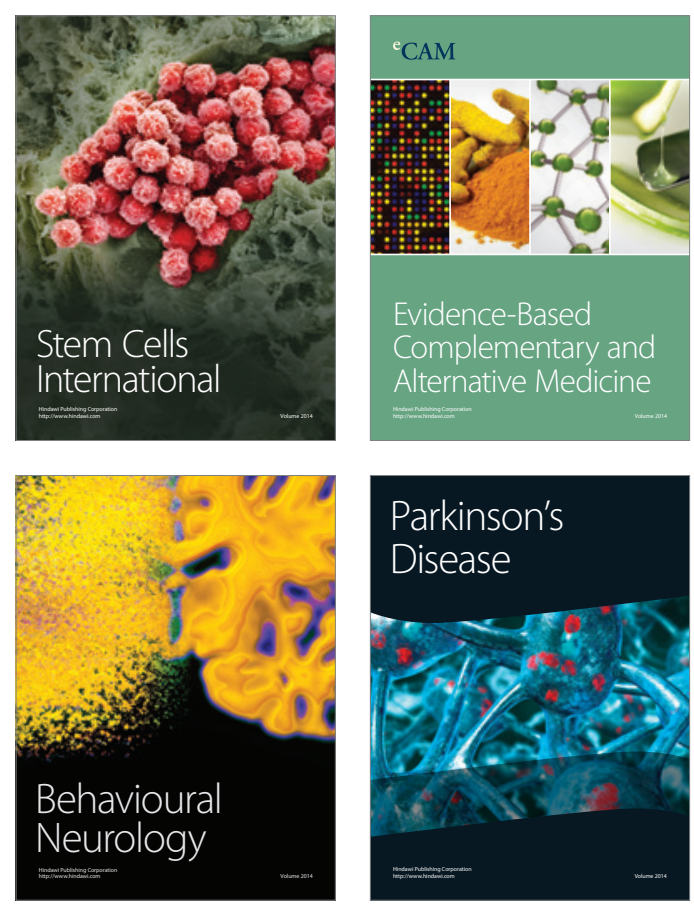

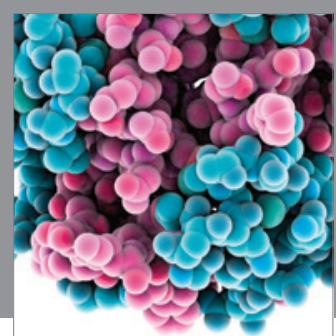

Journal of
Diabetes Research

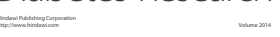

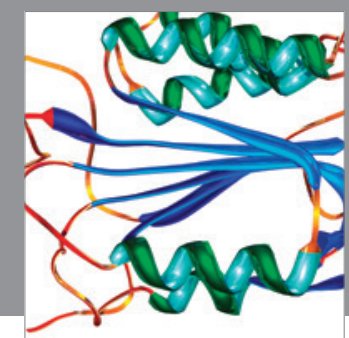

Disease Markers
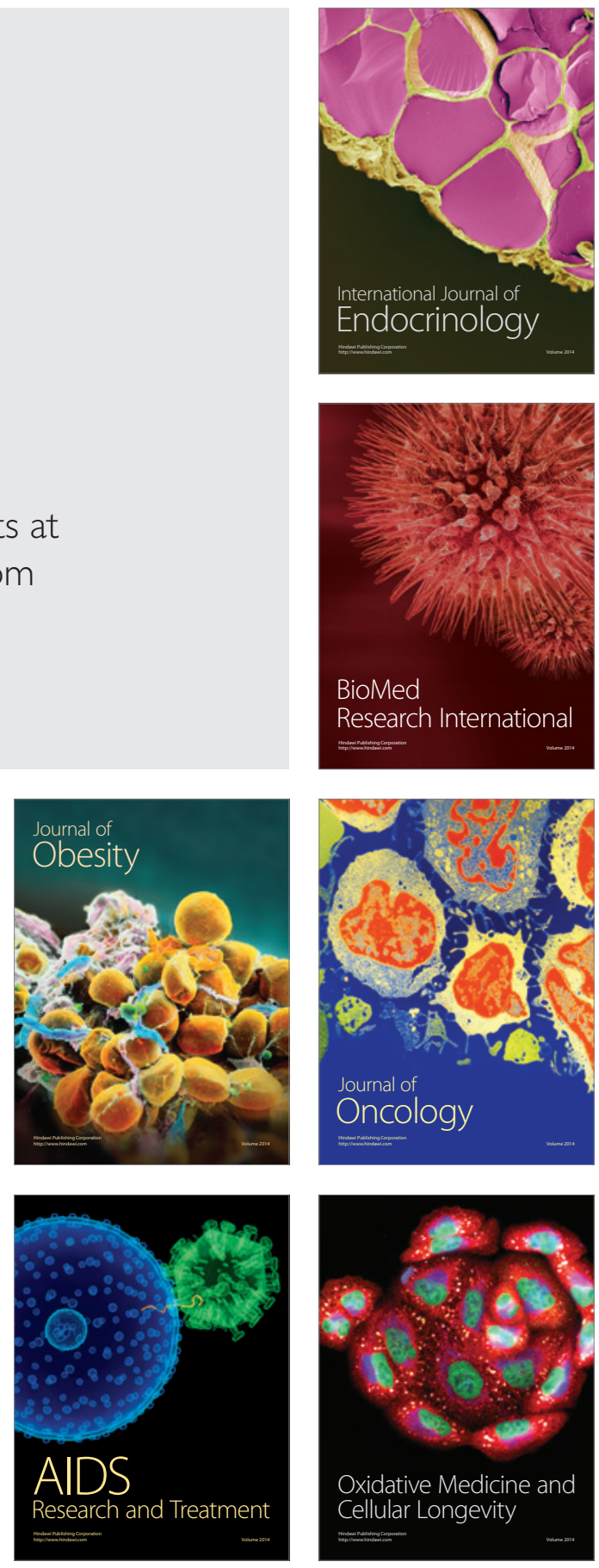